\title{
ASO Author Reflections: Amputation for Extremity Sarcoma
}

\author{
Derek J. Erstad, MD \\ Department of Surgery, Massachusetts General Hospital, Harvard Medical School, Boston, MA
}

\section{PAST}

For patients with extremity sarcoma (ES), the landmark National Cancer Institute phase 3 trial demonstrated no difference in overall survival between treatment using limb-sparing surgery (LSS) with external beam radiotherapy (EBRT) and treatment using primary amputation. ${ }^{1}$ Accordingly, LSS has become the standard of care, and $<10 \%$ of patients with ES are treated with amputation in the modern era. ${ }^{2}$ The subset of patients still requiring amputation for treatment of ES have worse survival, ${ }^{3}$ likely due to larger, more aggressive tumors. However, less is known about the indication and outcome for patients requiring amputation after an initial LSS (delayed amputation for recurrence) and about how these patients compare with those requiring primary amputation.

\section{PRESENT}

This retrospective analysis identified similar indications for primary and delayed amputation. ${ }^{4}$ The most common indication was loss of limb function from direct tumor invasion or anticipated loss of function due to lack of a viable function-sparing surgical salvage option. Notably, survival did not differ between early and delayed amputation cohorts measured from the time of diagnosis, although a trend toward improved outcome was observed with primary amputation. Additionally, the delayed cohort had a higher rate of post-amputation distant metastases.

ASO Author Reflections offer a brief invited commentary on the article, Amputation for Extremity Sarcoma: Contemporary Indications and Outcomes. Ann Surg Oncol. 2018;25:394-403.

(C) Society of Surgical Oncology 2018

First Received: 7 November 2018; Published Online: 17 December 2018

D. J. Erstad, MD

e-mail: derstad@partners.org
Prior studies have demonstrated decreased survival for patients requiring primary amputation, and the findings of the current study suggest that delayed amputation also is an adverse prognostic marker. Notably, the cohort with delayed amputation was more likely to present with proximal tumors and thus required more morbid amputations at the time of recurrence.

\section{FUTURE}

The optimal management of patients with ES requiring amputation in the modern era remains an important area of investigation. The results of this and other studies demonstrate that patients who require amputation for ES have a worse outcome despite a lower rate of local recurrence, indicating a fundamental difference in tumor biology. Recent advances in genomics, proteomics, and bioinformatics may allow clinicians to better characterize and target unique adverse biologic traits of ES tumors that require amputation. Such findings are critical to the development of better systemic therapies, which are ultimately needed to improve outcomes for this patient population.

DISCLOSURE The authors have no conflicts of interest to disclose.

\section{REFERENCES}

1. Rosenberg SA, Tepper J, Glatstein E, Costa J, Baker A, Brennan $\mathrm{M}$, et al. The treatment of soft tissue sarcomas of the extremities: prospective randomized evaluations of (1) limb-sparing surgery plus radiation therapy compared with amputation and (2) the role of adjuvant chemotherapy. Ann Surg. 1982;196:305-15.

2. Pitcher ME, Fish S, Thomas JM. Management of soft tissue sarcoma. Br J Surg. 1994;81:1136-9.

3. Williard WC, Hajdu SI, Casper ES, Brennan MF. Comparison of amputation with limb-sparing operations for adult soft tissue sarcoma of the extremity. Ann Surg. 1992;215:269-75.

4. Erstad DJ, Ready J, Abraham J, Ferrone ML, Bertagnolli MM, Baldini EH, Raut CP. Amputation for extremity sarcoma: contemporary indications and outcomes. Ann Surg Oncol. 2018;25:394-403. 